\title{
The Effect of Particle Composition and Concentration on the Partitioning Coefficient for Mercury in Three Ocean Basins
}

\author{
XINYUN CUI ${ }^{1}$, CARL LAMBORG $^{1}$, CHAD \\ HAMMERSCHMIDT $^{2}$, YANG XIANG ${ }^{1}$ AND PHOEBE J. \\ LAM $^{1}$ \\ ${ }^{1}$ University of California, Santa Cruz \\ ${ }^{2}$ Wright State University \\ Presenting Author: xcui12@ucsc.edu
}

The downward flux of sinking particles is a prominent $\mathrm{Hg}$ removal and redistribution process in the ocean; however, it is not well constrained. Using data from three U.S. GEOTRACES cruises including the Pacific, Atlantic and Arctic Oceans, we examined the mercury partitioning coefficient in the water column. The data suggest that the $K_{\mathrm{d}}$ varies widely over three ocean basins. We also investigated the effect of particle concentration and composition on $K_{\mathrm{d}}$ by comparing the concentration of small-sized $(1-51 \mu \mathrm{m})$ suspended particulate mass (SPM) as well as its compositional fractions in six different phases to the partitioning coefficient. We observed an inverse relationship between $K_{\mathrm{d}}$ and suspended particulate mass, as has been observed for other metals and known as the "particle concentration effect", that explains much of the variation in $K_{\mathrm{d}}$. Particulate organic matter (POM) and calcium carbonate $\left(\mathrm{CaCO}_{3}\right)$ dominated the $\mathrm{Hg}$ partitioning in all three ocean basins while Fe and Mn could make a difference in some places where their concentrations are elevated, such as in hydrothermal plumes. Finally, our estimated $\mathrm{Hg}$ residence time has a strong negative correlation with average $\log$ bulk $K_{\mathrm{d}}$, indicating that $K_{\mathrm{d}}$ has significant effect on $\mathrm{Hg}$ residence time. 